\title{
Synthesis, photoluminescence and electrochemical properties of 2,7-diarylfluorene derivatives
}

\author{
NEERAJ AGARWAL*, PABITRA K NAYAK and N PERIASAMY* \\ Department of Chemical Sciences, Tata Institute of Fundamental Research, Homi Bhabha Road, \\ Colaba, Mumbai 400005 \\ e-mail: peri@tifr.res.in
}

MS received 8 May 2008; revised 16 June 2008

\begin{abstract}
A new class of highly fluorescent 9,9'-bis-(alkyl)-2,7-diarylfluorene having electron withdrawing or electron donating groups on the $p$-phenyl positions were synthesized and characterized. The highly luminescent fluorene derivatives, 1-6 showed blue emission (376-416 nm), narrow FWHM $(\sim 50 \mathrm{~nm})$, high quantum yield $\left(\phi_{\mathrm{F}}=0 \cdot 12-0 \cdot 87\right)$ and short fluorescence lifetimes, $\tau_{\mathrm{F}}=0 \cdot 23-1 \cdot 14 \mathrm{~ns}$. The HOMO levels of 9,9'-bis-(alkyl)-fluorene were tuned by the $p$-substituents at 2,7-phenyl group. Hammett correlation with $E_{\mathrm{HOMO}}$ of these new molecules provides an effective tool to predict the HOMO level of similar molecules prior to the synthesis. These data indicate that they are useful as emitting materials for organic light emitting devices, OLEDs.
\end{abstract}

Keywords. Fluorene; DFT calculation; blue emitters; HOMO level and OLED.

\section{Introduction}

Organic light-emitting device (OLED) is recognized as a promising display and lighting technology. ${ }^{1}$ White organic light-emitting devices are becoming important for practical applications such as solidstate lighting and backlight illumination for liquidcrystal displays. ${ }^{2}$ Development of new electroluminescent materials is an active area of research because of their use in display as carrier transporters and/or emitters. ${ }^{3}$ Use of organic molecules as electronic materials is fascinating due to the availability of a vast variety of molecules and easy control of their properties by simple chemical modifications. Blue, green and red emitters having good stability, high luminescence quantum yield and colour purity are required for the fabrication of full colour displays. ${ }^{4}$ Green ${ }^{5}$ and red $^{6}$ emitting OLEDs have already been achieved with high brightness and efficiency, which satisfactorily meet the requirements for commercial applications. Blue-emitting materials are important not only as blue emitters, but also as hosts for phosphorescent dopants for green and red emission. ${ }^{7}$ Although current blue-emitting OLEDs ${ }^{8}$ have not been fully optimized, there remains a strong demand to develop new blue emitters for OLEDs.

*For correspondence
Blue emitting materials have the band gap $\sim 2.9 \mathrm{eV}$. However, for a successful electronic device operation it is necessary to have HOMO and LUMO levels of organic molecules aligned with the Fermi levels of commonly used anode (e.g. ITO or Au) and cathode (e.g. $-2.9 \mathrm{eV}$ for $\mathrm{Ca}$ and $-4.2 \mathrm{eV}$ for $\mathrm{Al}$ ). ${ }^{9}$ The energy levels can be tuned by electron withdrawing and donating groups in the conjugated molecules. The other desirable physical properties are high solubility in organic solvents, ability to form pin hole-free thin films, high quantum yield in thin film and high mobility for hole or electron.

Fluorene was chosen as the core conjugated structure in this study because of polyfluorene has intense luminescence, ${ }^{10}$ high hole mobility ${ }^{11}$ and widely used $^{12}$ in OLEDs. The reported molecules emit in green or blue-green, and not in 'true' blue region of $400-430 \mathrm{~nm}$. In this paper, we report the one pot synthesis of a few fluorene derivatives, their characterization and properties.

\section{Experimental}

All the solvents were obtained from $\mathrm{M} / \mathrm{s}$ SD Fine Chemicals (India). Aryl boronic acid(s) were either purchased from Aldrich or synthesized. 2,7-dibromo9,9'-(2-ethylhexyl)-fluorene, 9,9'-dihexyl-fluorenyl- 
2,7-boronic acid, $\mathrm{K}_{2} \mathrm{CO}_{3}$, were purchased from $\mathrm{M} / \mathrm{s}$ Sigma-Aldrich and were used as received. $\mathrm{Pd}\left(\mathrm{PPh}_{3}\right)_{4}$ was freshly prepared using $\mathrm{PdCl}_{2}$ and $\mathrm{PPh}_{3} \cdot{ }^{13}$ Reactions were carried out under inert atmosphere of nitrogen in oven-dried glasswares. Progress of reaction was monitored using Silica Gel TLC plates and UV detection (254 and $365 \mathrm{~nm}$ ). Silica gel (100-200 mesh) was used for column chromatography.

${ }^{1} \mathrm{H}$ and ${ }^{13} \mathrm{C}$ NMR spectra were recorded using Bruker spectrometer with working frequency of $500 \mathrm{MHz}$ for ${ }^{1} \mathrm{H}$ NMR and $125 \mathrm{MHz}{ }^{13} \mathrm{C}$ NMR. The chemical shifts were referenced to TMS (added) or $\mathrm{CHCl}_{3}$ present as impurity in $\mathrm{CDCl}_{3}$. Mass spectra were measured using MALDI-TOF mass spectrometer. Photoluminescence were measured using SPEX Fluorolog 1681. Quantum yields were calculated using Anthracene standard. Photoluminescence decays were measured using Time Correlated Single Photon Counting (TCSPC) method. ${ }^{14}$ Cyclic voltammetry was done using $\mathrm{CH}$ Instruments $600 \mathrm{C}$. Oxidation potentials were determined with respect to ferrocene as internal standard.

\subsection{Synthesis of 2,7-diphenyl-9,9'-bis-(2-ethylhexyl)- fluorene, 1}

2,7-dibromo-9,9'-bis-(2-ethylhexyl)-fluorene $(0 \cdot 37 \mathrm{~g}$, $0.68 \mathrm{mmol})$, phenylboronic acid $(0.18 \mathrm{~g}, 1.52 \mathrm{mmol})$, $\mathrm{Pd}\left(\mathrm{PPh}_{3}\right)_{4}(0.03 \mathrm{~g}, 0.026 \mathrm{mmol})$ and $\mathrm{K}_{2} \mathrm{CO}_{3}(0.6 \mathrm{~g}$, $4.3 \mathrm{mmol}$ ) were placed under inert atmosphere in a reaction vessel. 1,2-dimethoxyethane $(5.0 \mathrm{~mL})$ and water $(5.0 \mathrm{~mL})$ were added while purging nitrogen. The reaction mixture was stirred at $80^{\circ} \mathrm{C}$ for approximately $16 \mathrm{~h}$. After cooling the reaction mixture to room temperature, dichloromethane was added and organic layer was separated from aqueous layer. Aqueous layer was washed three times with dichloromethane. All organic layers were combined and washed with brine and dried over $\mathrm{Na}_{2} \mathrm{SO}_{4}$. The solvent was evaporated to get the crude product. Silica gel column chromatography using a mixture of hexanes and ethyl acetate $(9: 1)$ as eluent afforded the pure compound as white solid. Yield: $0.26 \mathrm{~g}, 73 \%$; m.p: $76^{\circ} \mathrm{C} ;{ }^{1} \mathrm{H}$ NMR $\left(500 \mathrm{MHz}, \mathrm{CDCl}_{3}\right): 0 \cdot 51-0.86(\mathrm{~m}$, $30 \mathrm{H}$, aliphatic chain); $2.02-2.08\left(m, 4 \mathrm{H}, \mathrm{CH}_{2}\right), 7.37$ $(d, 2 \mathrm{H}, J=7.8 \mathrm{~Hz}), 7.45-7.48(\mathrm{~m}, 4 \mathrm{H}), 7.56-7.65(\mathrm{~m}$, $8 \mathrm{H}), 7.75(d, 2 \mathrm{H}, J=7.3 \mathrm{~Hz}) ;{ }^{13} \mathrm{C}$ NMR $(125 \mathrm{MHz}$, $\left.\mathrm{CDCl}_{3}\right): 10 \cdot 38,13 \cdot 94,22 \cdot 72,27 \cdot 11,28 \cdot 21,33 \cdot 83$, $34 \cdot 68,44 \cdot 54,55 \cdot 08,119.94,122 \cdot 81,126 \cdot 10,126 \cdot 96$, $127.14,128.69,139.53,140.26,141.93,151.24$; MALDI-TOF for $\mathrm{C}_{41} \mathrm{H}_{50}$ Calcd. 542.84, Found 543.03;
Elemental analysis: Calcd. C, 90.72; H, 9.28, Found. C, $90.89 ; \mathrm{H}, 9.63$.

\subsection{Synthesis of 2,7-bis-(4-methoxyphenyl)-9,9'- bis-(2-ethylhexyl)-fluorene, 2}

2,7-dibromo-9,9'-bis-(2-ethylhexyl)-fluorene (0.36 g, $0.66 \mathrm{mmol})$, 4-methoxyphenylboronic acid $(0.23 \mathrm{~g}$, $1.50 \mathrm{mmol}), \operatorname{Pd}\left(\mathrm{PPh}_{3}\right)_{4}(0.30 \mathrm{~g}, 0.026 \mathrm{mmol})$ and $\mathrm{K}_{2} \mathrm{CO}_{3}(0.6 \mathrm{~g}, 4.3 \mathrm{mmol})$ were placed in a reaction vial under inert atmosphere. 1,2-Dimethoxyethane $(5.0 \mathrm{~mL})$ and water $(5.0 \mathrm{~mL})$ were added. The reaction vial was evacuated followed by the nitrogen purging and the reaction mixture was stirred at $80^{\circ} \mathrm{C}$ for $17 \mathrm{~h}$. After cooling the reaction mixture, dichloromethane was added and aqueous layer was separated and washed three times with dichloromethane. All organic layers were combined and washed with brine. The organic solvent was evaporated on rotary evaporator to get the brown coloured crude product. Silica gel column chromatography using a mixture of hexanes and ethyl acetate $(9: 1)$ afforded the pure compound 2 as soft white solid. Yield: $0.22 \mathrm{~g}, 57 \%$; m.p.: $96^{\circ} \mathrm{C}$, FT-IR: $2955 \mathrm{~cm}^{-1}\left(-\mathrm{OCH}_{3}\right) ;{ }^{1} \mathrm{H}$ NMR $\left(500 \mathrm{MHz}, \mathrm{CDCl}_{3}\right): 0.52-0.92(\mathrm{~m}, 30 \mathrm{H}$, aliphatic chain); 2.02-2.07 (m, 4H, $\left.\mathrm{CH}_{2}\right) ; 3.80\left(s, 6 \mathrm{H}, \mathrm{OCH}_{3}\right)$, 7.00-7.02 ( $m, 4 \mathrm{H}$, phenyl), 7.51-7.58 ( $m, 8 \mathrm{H}$, fluorene and phenyl); 7.72-7.73 (d, 2H, $J=7.5 \mathrm{~Hz}) ;{ }^{13} \mathrm{C}$ NMR (125 MHz, $\left.\mathrm{CDCl}_{3}\right): 10 \cdot 34,13 \cdot 95,22 \cdot 69,27 \cdot 09$, $28 \cdot 17,33 \cdot 81,34 \cdot 64,44 \cdot 54,54 \cdot 95,55 \cdot 34,114 \cdot 15$, $119 \cdot 71,122 \cdot 37,125 \cdot 62,128 \cdot 08,134 \cdot 55,138 \cdot 97,139 \cdot 79$, 151.13, 158.94; MALDI-TOF for $\mathrm{C}_{43} \mathrm{H}_{54} \mathrm{O}_{2}$ Calcd. 602.89, Found 602.74; Elemental analysis: Calcd. C, 85.66; H, 9.03, Found C, 85.43; H, 9.67.

\subsection{Synthesis of 2,7-bis-(4-cyanophenyl)-9,9'-bis- (2-ethylhexyl)-fluorene, 3}

2,7-dibromo-9,9'-bis-(2-ethylhexyl)-fluorene $(0.36 \mathrm{~g}$, $0.67 \mathrm{mmol}), 4$-cyanophenylboronic acid $(0.22 \mathrm{~g}$, $1.52 \mathrm{mmol}), \mathrm{Pd}\left(\mathrm{PPh}_{3}\right)_{4}(0.30 \mathrm{~g}, 0.026 \mathrm{mmol})$ and $\mathrm{K}_{2} \mathrm{CO}_{3}(0.6 \mathrm{~g}, 4.3 \mathrm{mmol})$ were placed under inert atmosphere in a screw cap vial. 1,2-dimethoxyethane $(5.0 \mathrm{~mL})$ and water $(5.0 \mathrm{~mL})$ were added under and the reaction vial was evacuated followed by the nitrogen purging (three cycles) and the reaction mixture was stirred at $80^{\circ} \mathrm{C}$ for $16 \mathrm{~h}$. Dichloromethane was added to the reaction mixture and aqueous layer was separated followed by the washing with dichloromethane. All organic layers were combined and evaporated on rotary evaporator to get the crude product. 
Purification by column chromatography using hexanes and ethyl acetate $(9: 1)$ afforded the pure compound 3 as white solid. Yield: $0.3 \mathrm{~g}, 76 \%$; m.p.: $157^{\circ} \mathrm{C}$; FT-IR: $2225 \mathrm{~cm}^{-1}(-\mathrm{CN}) ;{ }^{1} \mathrm{H}$ NMR $(500 \mathrm{MHz}$, $\left.\mathrm{CDCl}_{3}\right): 0.55-0.89(\mathrm{~m}, 30 \mathrm{H}$, aliphatic chain); 2.06$2 \cdot 10\left(m, 4 \mathrm{H}, \mathrm{CH}_{2}\right), 7.59-7.62$ ( $m, 4 \mathrm{H}$, phenyl), 7.72$7.75(m, 8 \mathrm{H}$, fluorene and phenyl); 7.83-7.84 $(d, 2 \mathrm{H}$, $J=7.5 \mathrm{~Hz}) ;{ }^{13} \mathrm{C}$ NMR $\left(125 \mathrm{MHz}, \mathrm{CDCl}_{3}\right): 10 \cdot 36$, $13.90,22 \cdot 65,27 \cdot 16,28 \cdot 17,33 \cdot 86,34 \cdot 78,44 \cdot 41$, $55 \cdot 31,110 \cdot 72,118 \cdot 98,120 \cdot 57,122 \cdot 90,126 \cdot 42,127 \cdot 62$, $132 \cdot 63,137 \cdot 84,141 \cdot 14,146 \cdot 07,151 \cdot 74$; MALDITOF for $\mathrm{C}_{43} \mathrm{H}_{48} \mathrm{~N}_{2}$ Calcd. 592.85, Found 593.87; Elemental analysis: Calcd. C, 87.11; H, 8.16; N, 4.73, Obsd. C, 87.07; H, 8.16; N, 5.18.

\subsection{Synthesis of 2,7-bis-(4-acetylphenyl)-9,9'-bis- (2-ethylhexyl)-fluorene, 4}

In a reaction vessel, 2,7-dibromo-9,9'-bis-(2-ethylhexyl)-fluorene $(0.36 \mathrm{~g}, 0.67 \mathrm{mmol})$, 4-acetylphenylboronic acid $(0.25 \mathrm{~g}, 1.50 \mathrm{mmol}), \mathrm{Pd}\left(\mathrm{PPh}_{3}\right)_{4}(0.35 \mathrm{~g}$, $0.03 \mathrm{mmol})$ and $\mathrm{K}_{2} \mathrm{CO}_{3}(0.6 \mathrm{~g}, 4.3 \mathrm{mmol}), 1,2$-dimethoxyethane $(5.0 \mathrm{~mL})$ and water $(5.0 \mathrm{~mL})$ were placed under nitrogen atmosphere and the reaction mixture was stirred at $80^{\circ} \mathrm{C}$ for $16 \mathrm{~h}$. Aqueous layer was separated from organic layer followed by washing thrice with dichloromethane. All organic layers were combined and evaporated to get the crude product. Purification by column chromatography using hexanes and ethyl acetate $(8: 2)$ gave the pure compound 4 as off white solid. Yield: $0.29 \mathrm{~g}, 72 \%$; m.p.: $95^{\circ} \mathrm{C}$; FT-IR: $\left.1675 \mathrm{~cm}^{-1}(-\mathrm{C}=0)\right) ;{ }^{1} \mathrm{H}$ NMR $(500 \mathrm{MHz}$, $\left.\mathrm{CDCl}_{3}\right): 0.57-0.92(\mathrm{~m}, 30 \mathrm{H}$, aliphatic chain); 2.07$2.13\left(m, 4 \mathrm{H}, \mathrm{CH}_{2}\right), 2.69\left(s, 6 \mathrm{H}, \mathrm{COCH}_{3}\right), 7 \cdot 64-7.67$ ( $m, 4 \mathrm{H}$, phenyl), 7.75-7.77 $(d, 4 \mathrm{H}, J=8.0 \mathrm{~Hz})$; $7.83-7.85(d, 2 \mathrm{H}, J=7.5 \mathrm{~Hz}), 8.08-8.10(d, 4 \mathrm{H}$, $J=8.5 \mathrm{~Hz}) ;{ }^{13} \mathrm{C}$ NMR $\left(125 \mathrm{MHz}, \mathrm{CDCl}_{3}\right): 10.35$, $13 \cdot 90,22 \cdot 66,26 \cdot 62,27 \cdot 16,28 \cdot 17,31 \cdot 55,33 \cdot 86$, $34 \cdot 74,44 \cdot 41,55 \cdot 21,120 \cdot 29,122 \cdot 94,123 \cdot 03,126 \cdot 37$, $127 \cdot 12,128 \cdot 93,135 \cdot 67,138 \cdot 39,140 \cdot 93,146 \cdot 29,151 \cdot 55$, 197.68; MALDI-TOF for $\mathrm{C}_{45} \mathrm{H}_{54} \mathrm{O}_{2}$ Calcd. 626.91, Found $625 \cdot 78$.

\subsection{2,7-bis-(4,4'-biphenyl)-9,9'-bis-(2-ethylhexyl)-} fluorene, 5

In a reaction vial, 2,7-dibromo-9,9'-bis-(2-ethylhexyl)fluorene $(0.36 \mathrm{~g}, 0.68 \mathrm{mmol}), 4,4^{\prime}$-biphenylboronic acid $(0.31 \mathrm{~g}, 1.52 \mathrm{mmol}), \mathrm{Pd}\left(\mathrm{PPh}_{3}\right)_{4}(0.30 \mathrm{~g}, 0.026 \mathrm{mmol})$ and $\mathrm{K}_{2} \mathrm{CO}_{3}(0.6 \mathrm{~g}, 4.3 \mathrm{mmol})$ were placed under nitrogen atmosphere. 1,2-dimethoxyethane $(5.0 \mathrm{~mL})$ and water $(5.0 \mathrm{~mL})$ were added under and the reaction vial was evacuated followed by the nitrogen purging (three cycles). The reaction mixture was stirred at $80^{\circ} \mathrm{C}$ for $18 \mathrm{~h}$. Aqueous layer was separated from organic layer followed by washing thrice with dichloromethane. All organic layers were combined and evaporated to get the impure product. Purification by column chromatography using hexanes and ethyl acetate $(8: 2)$ gave the pure compound 5 as off white solid. Yield: $0.31 \mathrm{~g}, 71 \%$; m.p: $126^{\circ} \mathrm{C},{ }^{1} \mathrm{H}$ NMR $\left(500 \mathrm{MHz}, \mathrm{CDCl}_{3}\right): 0.54-0.87(\mathrm{~m}, 30 \mathrm{H}$, aliphatic chain); $2 \cdot 10\left(m, 4 \mathrm{H}, \mathrm{CH}_{2}\right) ; 7.38(d, 2 \mathrm{H}, J=7 \cdot 3 \mathrm{~Hz})$, $7.48(m, 4 \mathrm{H}), 7.61-7.63(m, 2 \mathrm{H}), 7.66-7.68(m, 6 \mathrm{H})$, $7.70-7.73(m, 8 \mathrm{H}), 7.80(d, 2 \mathrm{H}, J=7.8 \mathrm{~Hz}) ;{ }^{13} \mathrm{C}$ NMR (125 MHz, $\left.\mathrm{CDCl}_{3}\right): 10 \cdot 37,22 \cdot 74,27 \cdot 13,33 \cdot 84$, $44 \cdot 59,55 \cdot 13,120 \cdot 06,122 \cdot 70,126 \cdot 01,126 \cdot 97,128 \cdot 78$, $138.87,139.05,139.84,140.37,140.83,151.33$; MALDI-TOF for $\mathrm{C}_{53} \mathrm{H}_{58}$ Calcd. 695.03, Found: 695.23.

\subsection{2,7-bis-(2,4-dimethoxy-1,3,5-triazine)-9,9'- dihexyl-fluorene, 6}

A reaction vessel was charged with 9,9'-dihexylfluorenyl-2,7-boronic acid $(0.42 \mathrm{~g}, 1.00 \mathrm{mmol})$, 2chloro-4,6-dimethoxy-1,3,5-triazine $(0.37 \mathrm{~g}, 2.1 \mathrm{mmol})$, $\mathrm{Pd}\left(\mathrm{PPh}_{3}\right)_{4}(0.50 \mathrm{~g}, 0.043 \mathrm{mmol})$ and $\mathrm{K}_{2} \mathrm{CO}_{3} 0.80 \mathrm{~g}$ $(5.8 \mathrm{mmol})$ under nitrogen atmosphere. Toluene $(5.0 \mathrm{~mL})$ and water $(5.0 \mathrm{~mL})$ were added and the reaction mixture was stirred at $110^{\circ} \mathrm{C}$ for $17 \mathrm{~h}$. After cooling the reaction mixture dichloromethane was added. Aqueous layer was separated and washed three times with dichloromethane. All organic layers were combined and washed with brine. The organic solvent was evaporated on rotary evaporator to get the crude product. Silica gel column chromatography using mixture of hexane and ethyl acetate $(8: 2)$ afforded the compound $\mathbf{6}$ as white solid. Yield: $0.47 \mathrm{~g}, 78 \%$; m.p: $168^{\circ} \mathrm{C},{ }^{1} \mathrm{H}$ NMR $\left(500 \mathrm{MHz}, \mathrm{CDCl}_{3}\right)$ : $0.57-0.60(m, 4 \mathrm{H}) .0 \cdot 70-0.73(\mathrm{~m}, 6 \mathrm{H}), 0.95-1.05(\mathrm{~m}$, $12 \mathrm{H}), 2 \cdot 10-2 \cdot 14\left(m, 4 \mathrm{H}, \mathrm{CH}_{2}\right), 4 \cdot 17\left(s, 12 \mathrm{H}, \mathrm{OCH}_{3}\right)$, $7.87(d, 2 \mathrm{H}, J=8.0 \mathrm{~Hz}), 8.51(s, 2 \mathrm{H}), 8.59(d, 2 \mathrm{H}$, $J=8.0 \mathrm{~Hz}$ ); MALDI-TOF for $\mathrm{C}_{35} \mathrm{H}_{44} \mathrm{~N}_{6} \mathrm{O}_{4}$ Calcd. 612.76, Found 613.95; Elemental analysis: Calcd. C, $68.60 ; \mathrm{H}, 7.24 ; \mathrm{N}, 13.72$, Found $\mathrm{C}, 67.42 ; \mathrm{H}, 7.04$; $\mathrm{N}, 12 \cdot 44$.

\subsection{2,7-di-(4-nitrophenyl)-9,9'-dihexyl-fluorene, 7}

9,9'-Dihexylfluorenyl-2,7-boronic acid $(0 \cdot 21 \mathrm{~g}, 0.5$ $\mathrm{mmol})$, 4-bromo-nitrobenzene $(0.21 \mathrm{~g}, 1.05 \mathrm{mmol})$, 
$\mathrm{Pd}\left(\mathrm{PPh}_{3}\right)_{4}(0.02 \mathrm{~g}, 0.017 \mathrm{mmol})$ and $\mathrm{K}_{2} \mathrm{CO}_{3}(0.4 \mathrm{~g}$, $2.9 \mathrm{mmol})$ were placed in a reaction vial under nitrogen atmosphere. Toluene $(5.0 \mathrm{~mL})$ and water $(5.0 \mathrm{~mL})$ were added. The reaction vial was evacuated followed by the nitrogen purging and the reaction mixture was stirred at $110^{\circ} \mathrm{C}$ for $17 \mathrm{~h}$. After cooling the reaction mixture dichloromethane was added and aqueous layer was separated and washed three times with dichloromethane. The organic layers were combined and were evaporated on rotary evaporator to get the dark crude product. Silica gel column chromatography using mixture of hexanes and ethyl acetate $(9: 1)$ afforded the pure compound 7 as yellow crystalline solid. Yield: $0 \cdot 2 \mathrm{~g}, 69 \%$; m.p: $127^{\circ} \mathrm{C},{ }^{1} \mathrm{H}$ NMR $\left(500 \mathrm{MHz}, \mathrm{CDCl}_{3}\right): 0 \cdot 70-0 \cdot 77(\mathrm{~m}$, $10 \mathrm{H}), 1.04-1.14(m, 12 \mathrm{H}), 2 \cdot 10\left(m, 4 \mathrm{H}, \mathrm{CH}_{2}\right), 7 \cdot 61(s$, $2 \mathrm{H}), 7.67(d, 2 \mathrm{H}, J=7.5 \mathrm{~Hz}), 7.83(d, 4 \mathrm{H}, J=9.0 \mathrm{~Hz})$, $7.87(d, 4 \mathrm{H}, J=8.0 \mathrm{~Hz}), 8.35(d, 4 \mathrm{H}, J=8.5 \mathrm{~Hz})$; MALDI-TOF for $\mathrm{C}_{37} \mathrm{H}_{40} \mathrm{~N}_{2} \mathrm{O}_{4}$ Calcd. 576.72, Found 577.82; Elemental analysis: Calcd. C, 77.06; $\mathrm{H}$, 6.99; N, 4.86, Found C, 76.96; H, 7.00; N, 5.07.

\section{Theoretical calculations}

Theoretical studies for of 9,9'-dimethyl fluorene and 2,7-diphenyl-9,9'-dimethyl fluorene were carried out by density functional theory (DFT) calculations using Gaussian $03 .{ }^{15}$ These calculations provided an insight on the distribution of the HOMO densities at different positions in the molecules. Figure la shows the contribution of $p_{z}$ atomic orbital for HOMO of 9,9'dimethylfluorene. It shows that 2- and 7-positions of fluorene have largest contribution to HOMO and hence the effect of electron donating and withdrawing groups in these positions would effect maximum
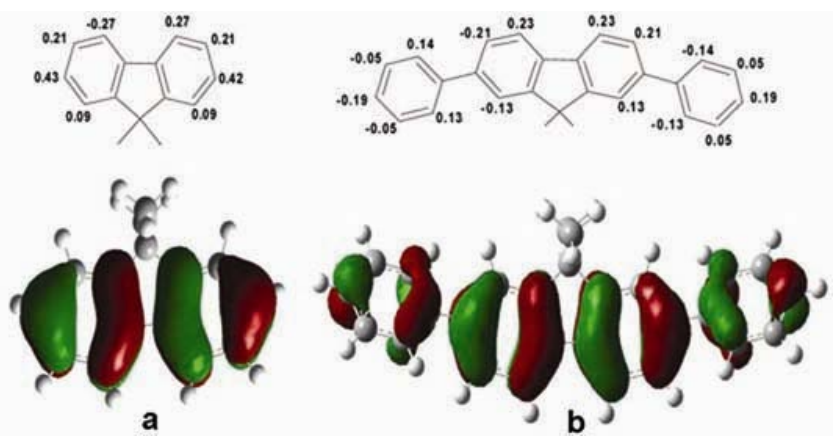

Figure 1. Representation of $p_{\mathrm{z}}$ contribution of the atomic orbitals for the HOMO (above) and molecular orbital plots (below) calculated using density functional theory (B3LYP/6-31G(d)) for (a) 9,9'-dimethylfluorene and (b) 2,7-diphenyl-9,9'-dimethylfluorene. changes in the HOMO level. DFT calculation of the model compound 2,7-diphenyl-9,9'-dimethylfluorene shows that ortho and para position of phenyl group contributes maximally to the HOMO (figure 1b). Hence, the substitution at ortho and para position of phenyl with electron withdrawing/donating groups should tune the HOMO energy level. Thus, the theoretical calculation on the core structure of diphenyl fluorene derivatives (1-7) is consistent with the experimental results, described below.

\section{Results and discussion}

Fluorene derivatives 1-7 were synthesized by SuzukiMiyaura cross-coupling ${ }^{16}$ (scheme 1). 1-5 were synthesized by reacting the 2,7-dibromo-9,9'-(2-ethylhexyl)-fluorene (1 eqv.) and aryl boronic acid ( $2 \cdot 2$ eqv.) and the reaction was catalysed by freshly prepared $\operatorname{Pd}\left(\mathrm{PPh}_{3}\right)_{4}$ in basic condition using 1,2-dimethoxyethane and water $(1: 1)$ as solvent. Heating the reaction mixture to $80^{\circ} \mathrm{C}$ and stirring for $16-20 \mathrm{~h}$ showed the completion of the reaction. Purification of crude product by silica gel column chromatography using hexanes and ethyl acetate mixture as eluent afforded fluorene derivatives 1-5 in 57-78\% yields. Compounds 6 and 7 were synthesized by Suzuki-Miyaura coupling of 9,9'-dihexyl-fluorenyl-2,7-diboronic acid and halogen derivatives with $\mathrm{Pd}\left(\mathrm{PPh}_{3}\right)_{4}$ and $\mathrm{K}_{2} \mathrm{CO}_{3}$ in toluene and water mixture. Crude reaction mixture was purified to get 6-7 in good yields. 1-7 were characterized by elemental analysis, spectroscopic methods: FT-IR, ${ }^{1} \mathrm{H}-\mathrm{NMR},{ }^{13} \mathrm{C}-\mathrm{NMR}, \mathrm{MALDI}-\mathrm{TOF}$. Solubility of 1-7 in chloroform is high $(\sim 25 \mathrm{mg} / \mathrm{mL})$.

Spectra of 2,7-diarylfluorene derivatives, 1-7, were studied. Absorption spectra of 1-7 showed $\pi$ $\pi^{*}$ transition at $328-375 \mathrm{~nm}$ in dichloromethane. For 6 the vibronic bands is also seen (figure 2). Substitutions at 2- and 7-position of fluorene (2-7) cause bathochromic shift with respect to 1 (table 1). Emission spectra of 1-7 were recorded in dichloromethane by excitation of the absorption band, and the spectra are shown in figure 3 . Compounds 1-6 showed emission in blue (376-416 nm) while compound 7 emitted in green at $532 \mathrm{~nm}$. Fluorescence quantum yields were measured with respect to anthracene $\left(\phi=0.27^{17}\right.$ in ethanol) and found to be in the range of $0 \cdot 12-0.87$ for 1-6. Compound 7 shows low quantum yield $(0.05)$ due to fluorescence quenching by nitro group. All values are given in table 1 . Solid film data are important for OLEDs and hence we also report the results for thin films of 1-7. Solid state 
<smiles>CCCCCCC(CC)(CCCC)C(CC)(CC)CCCCC</smiles><smiles>CCOC(=O)OCC(C)(C)C(=O)O</smiles><smiles>Cc1ccccc1</smiles><smiles>COc1ccc(C)cc1</smiles><smiles>Cc1ccc(C#N)cc1</smiles><smiles>Cc1ccc(C(=O)O)cc1</smiles><smiles>Cc1ccc(C2C=CC=CC2)cc1</smiles>
1

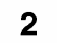

$$
3
$$

4<smiles>CCCCCCC(CC)(CCCCC)C(CC)(CCCC)c1cc([Al])ccc1-c1cccc(Cl)c1</smiles>
$57-76 \%$<smiles>CCCCCCCC(CCCCCC)c1cc(B(O)O)ccc1-c1ccc(B(O)O)cc1</smiles><smiles></smiles>

3 5<smiles>COc1nc(C)nc(OC)n1</smiles>

Scheme 1. Synthesis of fluorene derivatives 1-7.

Table 1. Photophysical and electrochemical data of 1-7.

\begin{tabular}{llllccc}
\hline Compd. & \multicolumn{1}{c}{${ }^{\mathrm{a}} \lambda_{\mathrm{Abs}}(\log \varepsilon)$} & ${ }^{\mathrm{a}} \lambda_{\mathrm{fl}}(\mathrm{ns})$ & ${ }^{\mathrm{a}} \tau(\mathrm{ns})$ & ${ }^{\mathrm{a}} \phi$ & ${ }^{\mathrm{b}} \lambda_{\mathrm{fl}}(\mathrm{nm})$ & ${ }^{\mathrm{b}} \tau(\mathrm{ns})$ \\
\hline $\mathbf{1}$ & $328(4 \cdot 72)$ & 360,376 & $0 \cdot 97^{\mathrm{c}}$ & 0.79 & 380 & $0 \cdot 26$ \\
$\mathbf{2}$ & $334(4 \cdot 63)$ & 370,387 & $0 \cdot 91^{\mathrm{c}}$ & $0 \cdot 79$ & 389 & $0 \cdot 42$ \\
$\mathbf{3}$ & $342(4 \cdot 64)$ & 387,403 & $0 \cdot 92^{\mathrm{c}}$ & $0 \cdot 87$ & 408 & $0 \cdot 66$ \\
$\mathbf{4}$ & $348(4 \cdot 60)$ & 416 & $0 \cdot 23^{\mathrm{d}}$ & $0 \cdot 12$ & 424 & $0 \cdot 28$ \\
$\mathbf{5}$ & $338(4 \cdot 84)$ & 387,404 & $0 \cdot 74^{\mathrm{c}}$ & $0 \cdot 78$ & 436 & $0 \cdot 47$ \\
$\mathbf{6}$ & $342(4 \cdot 86), 359(4 \cdot 87)$ & 372,391 & $1 \cdot 14^{\mathrm{c}}$ & $0 \cdot 95$ & 404 & $0 \cdot 04$ \\
$\mathbf{7}$ & $375(4 \cdot 53)$ & 532 & $1 \cdot 69^{\mathrm{d}}$ & $0 \cdot 05$ & 482 & $0 \cdot 21$ \\
\hline
\end{tabular}

${ }^{\mathrm{a}}$ In dichloromethane, ${ }^{\mathrm{b}} \mathrm{In}$ thin films, $\lambda_{\mathrm{fl}}=$ fluorescence emission, $\tau=$ average lifetime, $\phi=$ quantum yield, ${ }^{\mathrm{c}}$ Single lifetime was observed. ${ }^{\mathrm{d}}$ Lifetime components in dichloromethane for $4\left(\tau_{1}=0.212, \tau_{2}=0.588\right.$ and $\left.\alpha_{1}=0.955, \alpha_{2}=0.045\right)$ and for $7\left(\tau_{1}=0.294, \tau_{2}=1.703\right.$ and $\left.\alpha_{1}=0.011, \alpha_{2}=0.989\right)$. Average life time, $\tau=\sum \alpha_{i} \tau_{i} / \sum \alpha_{i}$

emission of 1-7 was studied by spin coated films on quartz plates and emission spectra are shown in figure 4. The emission peaks are red shifted compared to emission peaks in $\mathrm{CH}_{2} \mathrm{Cl}_{2}$ for 1-6. In case of 7 solid state emission is blue shifted (table 1). Fluorescence decays were measured by TCSPC technique. The PL decays were single exponential in solution except $\mathbf{4}$ and 7. Average lifetimes for multi-exponential decays were calculated and are given in table 1. Optical band gap $\left(S_{0}-S_{1}\right)$ of 1-7 was determined from the intersection of normalized emission and excitation spectra in thin films.

Redox peak potentials of 1-7 and stability of radical anion/cations were studied by cyclic voltammetry. 1-7 were characterized by quasi-reversible oxidation process, (conc. [1-7] $\sim 1 \mathrm{mM}$, tetrabutyl ammonium hexafluorophosphate $0 \cdot 1 \mathrm{M}$ as supporting electrolyte). A representative example of the cy- 
clic voltammogram of $\mathbf{2}$ is shown in figure 5. Peak potentials of 1-7 were determined with respect to ferrocene/ferrocenium redox couple and are found in the range of 0.82 to $1.30 \mathrm{~V}$. 1-7 were not reducible in the electrochemical range accessible in dichloromethane. The HOMO level was determined from the cyclic voltammetric peak potential. ${ }^{18,19}$ From this, the LUMO level was calculated by using $S_{0}-S_{1}$ gap. $^{19}$ The HOMO-LUMO levels of 1-7 are shown in table 2 . These results indicate that the electronic properties of the $p$-aryl group attached to the 2- and 7-positions of fluorene are directly correlated with the position of the HOMO level, supporting our initial notion for

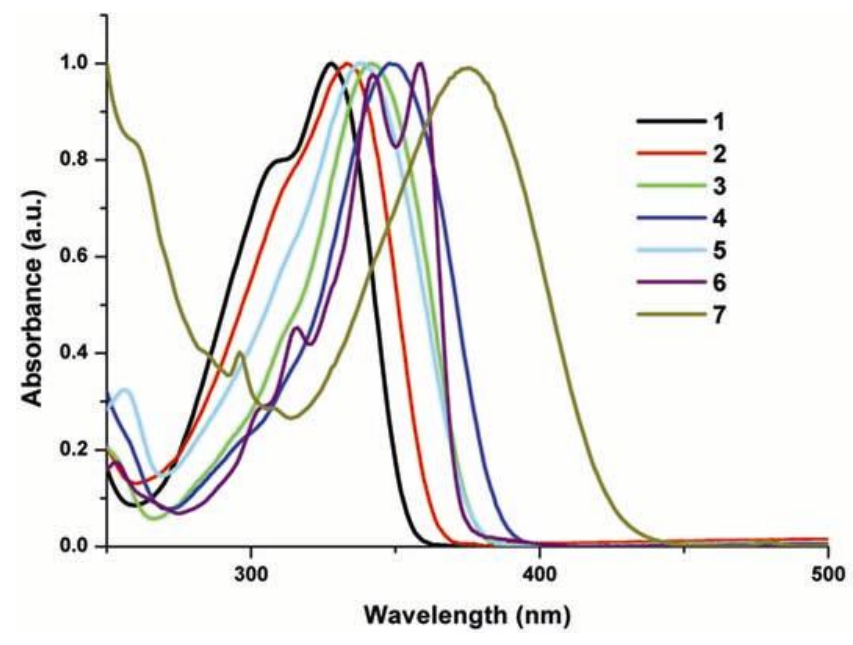

Figure 2. Normalized absorption spectra of 1-7 recorded in dichloromethane.

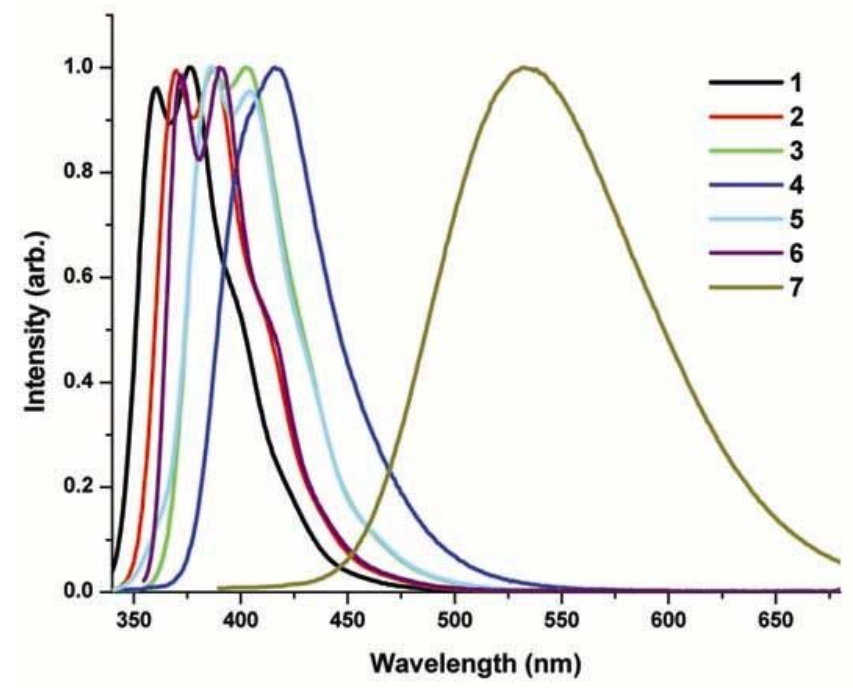

Figure 3. Normalized fluorescence spectra of 1-7 recorded in dichloromethane. tuning the emission of fluorene derivatives through 2- and 7-position, having the highest HOMO density.

Figure 6 shows a good correlation of $E_{\mathrm{HOMO}}$ with the Hammett constants $\sigma_{\mathrm{p}}$ for the substituents. This shows that the electron withdrawing/donating groups at $p$-phenyl position affects the $E_{\text {Hомо }}$ in accordance with the theoretical calculation on the core structure discussed earlier. This correlation plot may be used as a tool to predict the HOMO level of any substituent for which $\sigma_{\mathrm{p}}$ is known.

We have synthesized a series of fluorene derivatives having different substituents on 2- and 7positions. High solubility $(\sim 25 \mathrm{mg} / \mathrm{mL})$ of these compounds in chloroform makes them suitable for

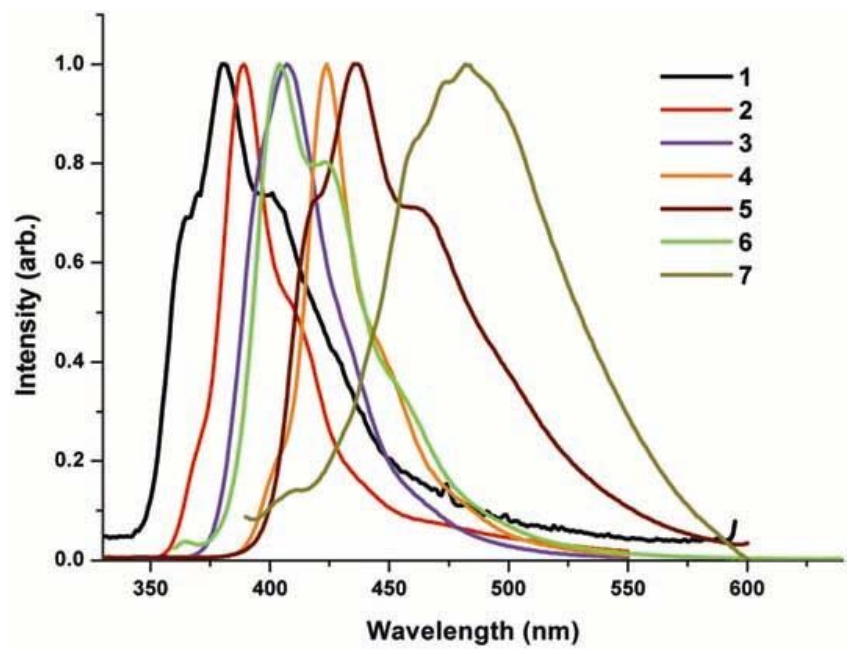

Figure 4. Solid state emission spectra of thin film of 1-7 on quartz plates.

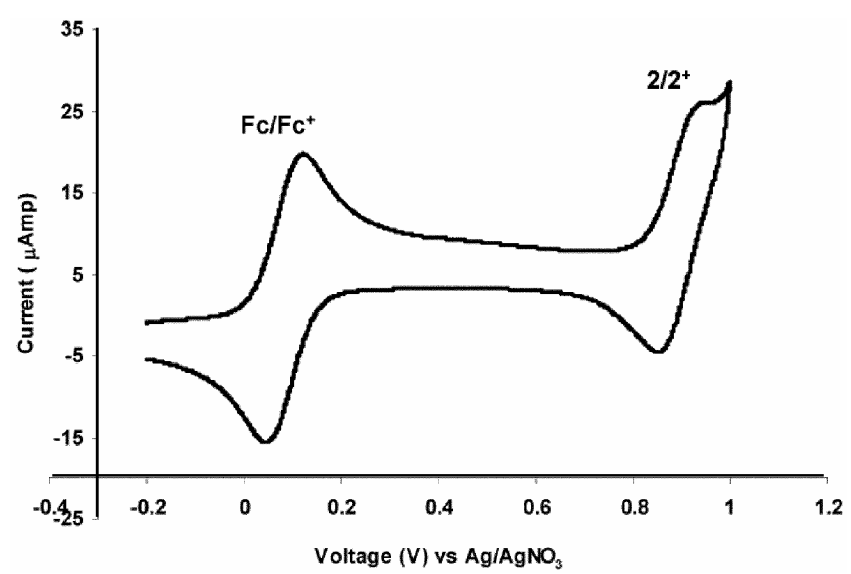

Figure 5. Cyclic voltammogram of $2(\sim 1 \mathrm{mM})$ recorded in acetonitrile using ferrocene $(\sim 1 \mathrm{mM})$ as internal reference and $\mathrm{Ag} / \mathrm{AgNO}_{3}$ as reference electrode. The redox couple $\mathrm{Fc} / \mathrm{Fc}^{+}$is reversible and $2 / 2^{+}$is quasi-reversible. 
Table 2. Electrochemical data for 1-7.

\begin{tabular}{|c|c|c|c|c|}
\hline Compound & ${ }^{\mathrm{a}} E p^{\mathrm{ox}}$ & ${ }^{\mathrm{b}} E_{\text {HOMO }}(\mathrm{eV})$ & $E_{\text {LUMO }}(\mathrm{eV})$ & Band gap $\left(S_{0}-S_{1}\right)$ \\
\hline $\mathbf{1}$ & 1.03 & $-5 \cdot 83$ & $-2 \cdot 41$ & $3 \cdot 42$ \\
\hline 2 & $0 \cdot 82$ & $-5 \cdot 62$ & $-2 \cdot 32$ & $3 \cdot 30$ \\
\hline 3 & $1 \cdot 22$ & $-6 \cdot 02$ & $-2 \cdot 90$ & $3 \cdot 12$ \\
\hline 4 & $1 \cdot 17$ & $-5 \cdot 97$ & $-2 \cdot 93$ & $3 \cdot 04$ \\
\hline 5 & $1 \cdot 00$ & $-5 \cdot 80$ & $-2 \cdot 78$ & $3 \cdot 02$ \\
\hline 6 & nd & - & - & $3 \cdot 13$ \\
\hline 7 & $1 \cdot 30$ & $-6 \cdot 10$ & $-3 \cdot 33$ & 2.77 \\
\hline
\end{tabular}

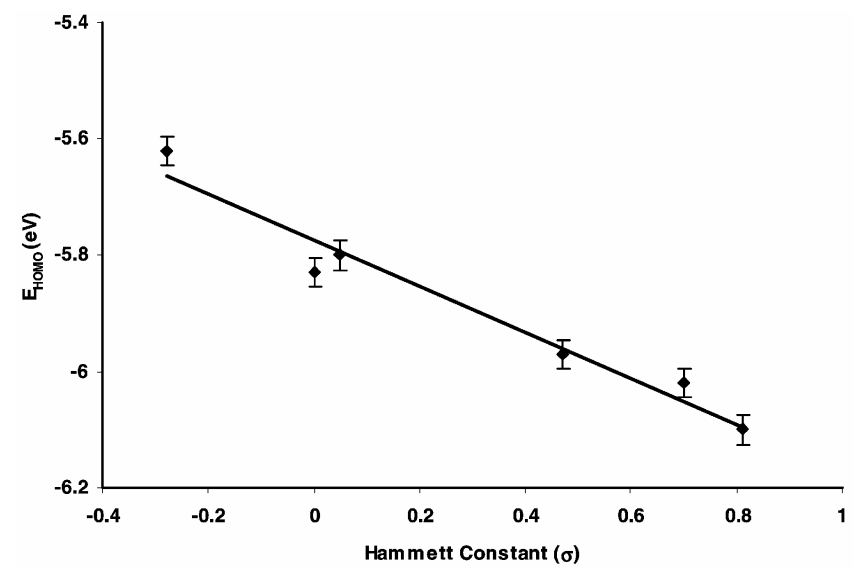

Figure 6. Correlation in $E_{\text {Hомо }}$ with Hammett constant for 1-5 and 7 .

large display panel by spin coat method. These compounds (1-6) have emission in true blue region and also have high quantum yield. Substituent at 2-and 7 -aryl tune the $E_{\text {HOMO }}$ level predictable by the Hammett constant of the substituents.

\section{Conclusion}

A few 2,7-diaryl-dialkyl-fluorene derivatives 1-7 were synthesized and characterized. These compounds show blue luminescence in solution and in solid state. The HOMO levels of the molecules are tuned by substituents, which is supported by theoretical calculations and experimental data.

\section{Supplementary material}

Selected ${ }^{1} \mathrm{H}$ NMR, ${ }^{13} \mathrm{C}$ NMR, PL decays and MALDITOF spectra are provided.

\section{Acknowledgements}

We are thankful to National Facility for high field NMR at TIFR for NMR spectra. We also thank Prof. K L Narasimhan for helpful discussions.

\section{References}

1. (a) Burroughes J H, Bradley D D C, Brown A B, Marks R N, Mackay K, Friend R H, Burn P L and Holmes A B 1990 Nature 347 539; (b) Baldo M A, Thompson M E and Forrest S R 2000 Nature 403750

2. (a) Kido J, Kimura M and Nagai K 1995 Science $\mathbf{2 6 7}$ 1332; (b) Kanno H, Giebink N C, Sun Y and Forrest S R 2006 Appl. Phys. Lett. 89023503

3. Shinar J 2003 Organic light-emitting devices (New York: Springer-Verlag)

4. Jordan R H, Dodabalapur A, Strukelj M and Miller T M 1996 Appl. Phys. Lett. 681192

5. (a) Kawamura Y, Goushi K, Brooks J, Brown J J, Sasabe $\mathrm{H}$ and Adachi C 2005 Appl. Phys. Lett. 86 071104; (b) Aziz H, Popovik Z D, Hu N-X, Hor A-M and Xu G 1999 Science 2381900

6. (a) Baldo M A, O'Brien D F, You Y, Shoustikov A, Sibley S, Thompson M E and Forrest S R $1998 \mathrm{Na}$ ture 395 151; (b) Li B, Li J, Fu Y and Bo Z $2004 J$. Am. Chem. Soc. 126 3430; (c) Montes V A, Pérez C, Agarwal N, Shinar J and Anzenbacher P Jr $2006 J$. Am. Chem. Soc. 12812436

7. (a) Okumoto K, Kanno H, Hamaa Y, Takahashi H and Shibata K 2006 Appl. Phys. Lett. 89 063504; (b) Zhang X H, Liu M W, Wong O Y, Lee C S, Kwong H L, Lee S L and Wu S K 2003 Chem. Phys. Lett. 369 478; (c) Chuen H and Tao Y T 2004 Appl. Phys. Lett. 854609

8. (a) Katsis D, Geng Y H, Ou J J, Culligan S W, Trajkovska A, Chen S H and Rothberg L J 2002 Chem. Mater. 14 1332; (b) Geng Y, Katsis D, Culligan S W, Ou J J, Chen S H and Rothberg L J 2002 Chem. Mater. 14 463; (c) Klaerner G and Miller R D 1998 Macromolecules 31 2007; (d) Yu W-L, Pei J, Huang W and Heeger A J 2000 Adv. Mater. 12 828; (e) Setayesh S, Grimsdale A C, Weil T, Enkelmann V, Mullen K, Meghdadi F, List E J W and Leising G 
2001 J. Am. Chem. Soc. 123 946; (f) Marsitzky D, Vestberg R, Blainey P, Tang B T, Hawker C J and Carter K R $2001 \mathrm{~J}$. Am. Chem. Soc. 1236965

9. Mueller G 2000 Electroluminescence II: Semiconductors and semimetal (San Diego: Academic Press)

10. Grice A W, Bardley D D C, Bernius M, Inbasekaran M, Wu W and Woo E P 1998 Appl. Phys. Lett. 73 629

11. Redecker M, Bardley D D C, Bernius M, Inbasekaran M and Woo E P 1999 Appl. Phys. Lett. 741400

12. (a) Whitehead K S, Grell M, Bardley D D C, Jandke $\mathrm{M}$ and Strohriegl P 2000 Appl. Phys. Lett. 76 2946; (b) Luo J, Zhou Y, Niu Z-Q, Zhou Q-F, Ma Y and Pei J 2007 J. Am. Chem. Soc. 129 11314; (c) Oyston S, Wang C, Hughes G, Batsanov A S, Perepichka I F, Bryce M R, Ahn J H, Pearsonb C and Petty M C 2005 J. Mater. Chem. 15 194; (d) Tao S, Lee C S, Lee S T and Zhang X 2007 Appl. Phys. Lett. 91 013507; (e)
Tao S L and Lee S T 2005 Adv. Funct. Mater. 15 1716

13. Coulson D R 1973 Inorg. Syn. 13121

14. Ira, Koti A S R, Krishnamoorthy G and Periasamy N 2005 J. Fluoresc. 1395

15. Frisch M J et al 2004 Gaussian 03, revision C.02; Gaussian, Inc.: Wallingford, CT

16. Miyaura N 2004 in Metal-catalysed cross-coupling reactions (eds) A De Meijere and $\mathrm{F}$ Diederich (Weinheim: Wiley-VCH)

17. Dawson W R and Windsow M W 1968 J. Phys. Chem. 72325

18. Andrade B W D, Datta S, Forrest S R, Djurovich P, Polikarpov E and Thompson M E 2005 Organic Electronics 611

19. Mishra A, Nayak P K, Ray D, Patankar M P, Narasimhan K L and Periasamy N 2006 Tetrahedron Lett. 474715 